\title{
Clinical presentation and comorbidities of obsessive compulsive disorders in children and adolescents presenting to a tertiary care hospital in Sri Lanka
}

\author{
YM Rohanachandra, WMML Chandradasa, DB Hettiarachchi, WKTR Fernando, \\ IAGMP Gunathilake, GS Wijetunge
}

\section{Background}

Obsessive compulsive disorder (OCD) in children differs from adults in that children do not show ego dystonicity, rarely have pure obsessions and commonly have pure compulsions with hidden obsessions. Comorbid psychiatric diagnoses are seen in more than $50 \%$ of children with OCD.

Aims

To describe the socio-demographic factors, clinical presentations and psychiatric comorbidities of children with OCD in a Sri Lanka setting, and to determine the factors associated with comorbidities.

Methods

A retrospective descriptive study design was used. Data was collected from clinic records of all patients diagnosed to have OCD at the child guidance clinic of Lady Ridgeway Hospital for Children, Colombo during the 3-year period from 2013-2016.

Results

Fifty two children were included in the study. The mean age of the children was 9.2 years. Males accounted for $71.2 \%$. The majority (55.8\%) had both obsessions and compulsions. Multiple obsessions were seen in $15.4 \%$ and multiple rituals in $26.9 \%$. The most common theme was contamination (61.5\%). Washing was the most common ritual (50\%). Comorbidities were present in $55.7 \%$, with attention deficit hyperactivity disorder (ADHD) (17.3\%) being the most common. Of the participants, $90.4 \%$ had impairments related to OCD. There was a significant association between the gender and the age of the child $(p=0.029)$ in the 5-10 year age group, boys were 5 times more common than girls, while the proportion of boys and girls were equal in children aged more than 10 years.

\section{Conclusion}

Comorbidities are common in childhood OCD, and all children with OCD should be screened for comorbidities.

Key words: obsessive compulsive disorder, comorbidity, children and adolescents

SL J Psychiatry 2016; 7(2): 16-19

\section{Introduction}

Obsessive-compulsive disorder (OCD) is characterised by persistent and unwanted intrusive thoughts, images and impulses (obsessions) and repetitive behaviours or mental acts (compulsions). In the past OCD was considered to be rare in children, but is now estimated to have a prevalence of approximately $0.25-4 \%$ (1).

OCD in children differs from adults in that children do not show ego dystonicity, rarely have pure obsessions in the absence of compulsions, and commonly have pure compulsions often with hidden or poorly articulated obsessions (2,3). Children's obsessions often center on a fear of a catastrophic family event (e.g., death of a parent) (2). Contamination, sexual, and somatic obsessions, and excessive scruples/guilt are also reported to be common (2). Washing, repeating, checking, and ordering are the most common compulsions (2).
Rituals such as verbal checking with parents to gain reassurance are also frequent (4).

Comorbid psychiatric diagnoses are seen in more than $50 \%$ of affected children, with comorbid attention-deficit hyperactivity disorder (ADHD), Tourette's syndrome, separation anxiety disorder, specific phobias and agoraphobia being seen in younger children, while older children had mood and psychotic disorders (2).

Clinical presentations and comorbidities in children with OCD in a Sri Lankan setting have not been studied to date, and most literature on childhood OCD is from developed countries. Better understandings of the presentations, comorbidities and cultural variations of children with OCD in Sri Lanka would be useful in planning and implementing treatment services for a Sri Lankan population. 


\section{Methods}

A retrospective descriptive study design was used for this study, which was conducted at the child guidance clinic of the Lady Ridgeway Hospital for Children, Colombo (LRH). The records of all patients diagnosed to have OCD by a consultant psychiatrist in accordance with the International Classification of Diseases $-10^{\text {th }}$ edition (ICD-10), during the 3-year period from 20132016 were included in the study. Data was collected retrospectively from clinic records, using a specially designed data extraction form. Chi square was used to determine the significance between groups. Ethics clearance for the study was obtained from the ethics clearance committee of LRH.

\section{Results}

Fifty-two children with OCD were included in the study. The mean age of the participants was 9.2 years. Of the participants, $61.5 \%(\mathrm{n}=32)$ were between $5-10$ years. Males accounted for $71.2 \%(n=37)$. Of the entire sample, $23.1 \%(\mathrm{n}=12)$ had a family history of OCD; $1.9 \%(\mathrm{n}=1)$ had developed OCD in the context of Paediatric Autoimmune Neuropsychiatric Disorder Associated with Streptococcal infection (PANDAS).

The majority $(55.8 \%, \mathrm{n}=29)$ had both obsessions and compulsions. Multiple obsessions were seen in $15.4 \%$ $(\mathrm{n}=8)$ and multiple rituals in $26.9 \%(\mathrm{n}=14)$. The most common theme was contamination $(61.5 \%, \mathrm{n}=32)$, followed by fear of catastrophic outcome $(15.38 \%, n=8)$. Washing was the most common ritual $(50 \%, n=26)$, followed by reassurance seeking $(23 \%, \mathrm{n}=11)$ (Table 1$)$. Comorbidities were present in 55.7\% $(\mathrm{n}=29)$. The most common comorbidity was $\operatorname{ADHD}(17.3 \%, \mathrm{n}=9)$, followed by tic disorder $(13.4 \%, n=7)$ (Figure 1$)$. Of the participants, $15.4 \%(\mathrm{n}=8)$ had more than one co-morbidity.

With regards to disability, $90.4 \%(\mathrm{n}=47)$ had impairments related to OCD, with $71.2(\mathrm{n}=37)$ having impairments at school. Academic decline was seen in $55.7 \%(\mathrm{n}=29)$ and $38.4 \%(n=20)$ had missed school after the onset of symptoms. Of the children affected with OCD, in $42.3 \%$ $(\mathrm{n}=22)$ it had impacted on their activities of daily living; and $5.7 \%(n=3)$ had developed behavioural problems related to the symptoms.

There was a significant association between the number of themes and presence of comorbidities. Children with a single theme had a higher rate of comorbidities $(\mathrm{p}=0.019)$. There was also a significant association between the gender distribution and the age of the child ( $\mathrm{p}=0.029$ ). In the 5-10 year age group, boys were 5 times more common than girls, while the proportion of boys and girls was equal in children aged more than 10 years.

\begin{tabular}{|c|c|}
\hline Clinical presentation & $\begin{array}{l}\text { oants who had } \\
\text { se features } \\
\%(n)\end{array}$ \\
\hline \multicolumn{2}{|l|}{ Type of presentation } \\
\hline Obsessions only & $25.0 \%(n=13)$ \\
\hline Compulsions only & $19.2 \%(n=10)$ \\
\hline Both obsessions and compulsions & $55.8 \%(n=29)$ \\
\hline \multicolumn{2}{|l|}{ Type of obsessions } \\
\hline Obsessional thoughts & $69.2 \%(n=36)$ \\
\hline Obsessional impulses & $3.8 \%(n=02)$ \\
\hline Obsessional doubts & $9.6 \%(n=05)$ \\
\hline Obsessional ruminations & $7.6 \%(n=04)$ \\
\hline Obsessional slowness & $5.7 \%(n=03)$ \\
\hline Obsessional images & $1.9 \%(n=01)$ \\
\hline \multicolumn{2}{|l|}{ Number of obsessions } \\
\hline Single & $67.3 \%(n=35)$ \\
\hline Multiple & $15.4 \%(n=08)$ \\
\hline No obsessions (Compulsions only) & $17.3 \%(n=09)$ \\
\hline \multicolumn{2}{|l|}{ Number of compulsions } \\
\hline Single & $50.0 \%(n=26)$ \\
\hline Multiple & $26.9 \%(n=14)$ \\
\hline No compulsions (Obsessions only) & $23.1 \%(n=12)$ \\
\hline \multicolumn{2}{|l|}{ Number of themes } \\
\hline Single & $78.8 \%(n=41)$ \\
\hline Multiple & $13.5 \%(n=07)$ \\
\hline Missing & $7.7 \%(n=04)$ \\
\hline \multicolumn{2}{|l|}{ Theme } \\
\hline Contamination & $61.5 \%(n=32)$ \\
\hline Catastrophic outcome & $15.3 \%(n=08)$ \\
\hline Symmetry & $13.4 \%(n=07)$ \\
\hline Sexual & $7.6 \%(n=04)$ \\
\hline IIIness & $5.7 \%(n=03)$ \\
\hline Missing & $5.7 \%(n=03)$ \\
\hline \multicolumn{2}{|l|}{ Type of ritual } \\
\hline Washing & $50.0 \%(n=26)$ \\
\hline Reassurance seeking & $23.0 \%(n=12)$ \\
\hline Ordering & $11.5 \%(n=06)$ \\
\hline Spitting & $9.6 \%(n=05)$ \\
\hline Checking & $7.6 \%(n=04)$ \\
\hline Repeating & $7.6 \%(n=04)$ \\
\hline Counting & $3.8 \%(n=02)$ \\
\hline
\end{tabular}

\section{Discussion}

OCD was considered to be a rare disorder in children and adolescents till the first epidemiological study in 1988, which showed that OCD is much more common among adolescents than was previously thought; it is often underdiagnosed and undertreated (5), and thus childhood OCD is sometimes referred to as a 'hidden epidemic' (2). 




SDDSS - Specific Developmental Disorder of Scholastic Skills

ADHD - Attention Deficit Hyperactivity Disorder

Figure 1. Proportions of varying behavioural and psychological symptoms of dementia among participants in this study.

Childhood OCD is a heterogenous condition, as in adults (6). Compared to adults, OCD in childhood is more characterised by obsessions that do not necessarily correspond well with overt symptoms and are more likely to lead to idiosyncratic behaviours (7). Higher rates of aggressive or harm related obsessions - such as fear of catastrophic events or fear of death or illnesses in self or parents - have been reported in children and adolescents compared to adults (4). This is consistent with the findings of the present study, where fear of a catastrophic outcome was found in $15.4 \%$ of the children, second only to contamination. Reassurance seeking has been shown to be a common ritual in children (4); again compatible with the findings of our study, where $23 \%$ of children reported reassurance seeking rituals. In contrast to previous studies, $9.6 \%$ of the children in this study had spitting as a ritual associated with obsessions of contamination, which to our knowledge has not been reported in the literature to date.

A few studies have reported a large proportion of children and young people with OCD to have clinically significant hoarding symptoms (8). Hoarding is reported to be more common in childhood OCD than in adults (8). However, none of the children in the sample we studied had hoarding symptoms. One possible reason for this could be that hoarding is related to a longer duration of illness (8). The present study did not look at the long term evolvement of symptoms and thus it is possible that the children in this study may develop such symptoms later in the illness.
Previous studies have shown a male to female ratio of $3: 2$ in children with OCD $(2,4)$. Our study showed a greater male preponderance, with a male to female ratio of 5:2. However, similar to previous studies, the male preponderance was seen in the younger age groups (less than 10 years) with the sex ratio being equal in children older than 10 years of age.

OCD is known to cause substantial impact on psychosocial functioning of children and adolescents $(9,10)$, with OCD related dysfunction being reported in more than $90 \%$ of children studied (10). Such impairment has been shown to be greatest at home, but school and social domains are also often affected (9). At home, OCD has been shown to particularly interfere with daily activities such as bathing and grooming and getting ready for bed (9). At school, OCD adversely impacts on activities such as getting to school on time, concentrating on work, school attendance and doing homework (9), which then lead to severe disruptions to academic performance (11). The proportion of children who had psychosocial dysfunction related to OCD in our study (90.4\%) was comparable with previous studies (10). In contrast to previous studies, in our study the adverse impact on school performance was higher than the impact on activities of daily living. One explanation for this difference could be the greater degree of family accommodation, combined with a higher focus on academic performance, in our culture compared with Western countries.

Previous studies have shown that about $50 \%$ of children with OCD have comorbid psychiatric illness 
(2), with attention-deficit hyperactivity disorder (ADHD), tic disorders, disruptive behavioural disorders, separation anxiety disorder and other anxiety disorders and mood disorders being more common $(2,12)$. The present study revealed similar findings, with $53.8 \%$ having co-morbid psychiatric disorders, of which ADHD (17.3\%) and tic disorders (13.4\%) were the most common. Thus, screening for co-morbid psychiatric disorders in childhood OCD is important, as those with comorbidities may require a different treatment approach; and also since the presence of comorbidities is associated with added disability and more severe dysfunction (12).

\section{Limitations}

The main limitation of our study is that it was carried out in a tertiary care hospital; children with more severe childhood OCD are often referred to this unit, hence our findings may not be directly generalisable to children with less severe symptoms. Missing or conflicting data due to the retrospective data collection from clinic records is another limitation.

\section{Conclusions}

Children with OCD in Sri Lanka may present with unusual rituals such as spitting, and clinicians need to be aware of these uncommon manifestations. As more than half the children studied had comorbidities, screening for comorbidities should be an integral part of assessment of childhood OCD. Given that a majority of the children had impairments at school, with more than half having academic decline after the onset of illness, liaison with the school is likely to be an important aspect of management.

\section{Declaration of interest}

None declared

YM Rohanachandra, Department of Psychiatry, Faculty of Medical Sciences, University of Sri Jayewardenepura

WMML Chandradasa, DB Hettiarachchi, WKTR Fernando, IAGMP Gunathilake, GS Wijetunge,

Lady Ridgeway Hospital for Children

Corresponding author: Y M Rohanachandra

Email: yasodha_mk@yahoo.com

\section{References}

1. Krebs G, Heyman I. Obsessive-compulsive disorder in children and adolescents. Arch Dis Child 2015; 100: 495-499.

2. Geller DA, March J. Practice parameter for the assessment and treatment of children and adolescents with obsessivecompulsive disorder. J Am Acad Child Adolesc Psychiatry 2012; 51 (1): 98-113.

3. Williams TI, Shafran R. Obsessive-compulsive disorder in young people. BJPsych Advances 2015; 21(3): 196205.

4. Boileau B. A review of obsessive-compulsive disorder in children and adolescents. Dialogues Clin Neurosci 2011; 13(4): 401-11.

5. Iament $\mathrm{M}$, Whitaker $\mathrm{A}$, Rapoport $\mathrm{J}$, et al. Obsessive compulsive disorder in adolescence: an epidemiological study. J Am Acad Child Adolesc Psychiatry 1988; 27: 764-71.

6. Ivarsson T, Valderhaug R. Symptom patterns in children and adolescents with obsessive-compulsive disorder (OCD). Behav Res Ther 2006; 44(8): 1105-16.

7. McKay D, Piacentini J, Greisberg S, et al. The structure of childhood obsessions and compulsions: Dimensions in an outpatient sample. Behav Res Ther 2006; 44(1): 137-46.

8. Mataix-Cols D, Nakatani E, Micali N, et al. Structure of obsessive-compulsive symptoms in pediatric OCD. J Am Acad Child Adolesc Psychiatry 2008; 47(7): 773-8.

9. Valderhaug R, Ivarsson T. Functional impairment in clinical samples of Norwegian and Swedish children and adolescents with obsessive-compulsive disorder. Eur Child Adolesc Psychiatry 2005; 14(3): 164-73.

10. Piacentini J, Bergman L, Keller M, et al. Functional Impairment in children and adolescents with obsessivecompulsive disorder. J Child Adolesc Psychopharmacol 2003; 13(1): 61-9.

11. Farrell LJ, Waters AM, Boschen MJ, et al. Responsibility beliefs, memory confidence, intolerance of uncertainty and the urge to check in childhood obsessive-compulsive disorder: an examination of cognitive theory. Behaviour Change 2011; 28(3): 128-42.

12. Geller DA, Biederman J, Griffin S, et al. Comorbidity of juvenile obsessive-compulsive disorder with disruptive behavior disorders. J Am Acad Child Adolesc Psychiatry 1996; 35(12): 1637-46. 